\title{
Rapid reduction in hospitalisations after an intervention to manage severe asthma
}

\author{
C. Souza-Machado*,\# , A. Souza-Machado\#, ", R. Franco" ${ }^{\#,+}$, E.V. Ponte ${ }^{\#}$, M.L. Barreto \\ L.C. Rodrigues ${ }^{f}$, J. Bousquet**\#\# and A.A. Cruz ${ }^{\#}$
}

ABSTRACT: Asthma is the third cause of hospitalisations due to clinical illnesses in Brazil. The Programme for Control of Asthma in Bahia (ProAR) leads an initiative in Salvador City (Brazil) to manage severe asthma for free. The aim of this study was to identify trends in asthma hospitalisation in the entire city and to evaluate the impact of ProAR.

Information on asthma hospitalisations from 1998 to 2006 was collected. We analysed trends in Salvador (2.8 million inhabitants) before and after ProAR, taking pneumonia and myocardial infarction into account for local comparison. As an external control we obtained information on asthma from Recife, which is the most comparable Brazilian city.

In Salvador, asthma hospital admissions declined by $82.3 \%$ (1998-2006). A greater proportion of this reduction (74\%) occurred after 2003, in parallel with the implementation of ProAR. The reduction in asthma admissions in Recife was smaller. The rates of hospitalisation in 2006 were 2.25 per 10,000 inhabitants in Salvador and $\mathbf{1 7 . 0 6}$ in Recife. In Salvador, we found an inverse correlation between the provision of medication for asthma and hospitalisation (-0.801; $\mathrm{p}<0.0001$ ).

A rapid reduction in asthma admissions in the entire city of Salvador was associated with ProAR, a public health intervention targeting severe asthma.

KEYWORDS: Asthma, hospitalisation, prevention, treatment

$\Delta$ sthma, a very common disease, is associated with the need for emergency department visits, risk of hospitalisations and deaths. Asthma exacerbations due to uncontrolled disease place a considerable burden on the healthcare system, in particular in developing countries [1]. In Latin America some 34 million individuals have asthma [2]. In Brazil, symptoms of asthma are found in $20 \%$ of the adolescents and asthma is the third cause of hospitalisations among all clinical illnesses $[3,4]$.

Secondary prevention using inhaled medication can reduce asthma exacerbations. A successful Finnish national asthma control programme markedly reduced asthma morbidity and mortality [5]. In Brazil and many Latin American countries there is no implementation of national strategies for asthma prevention or outpatient management. Isolated nonstandardised initiatives restricted to a few cities and focusing on distinct ages and asthma severity groups have been implemented [6].
The combination of a high prevalence of asthma and limited access to secondary prevention may have led to elevated morbidity and unacceptable mortality in Brazil. Morbidity due to asthma is not easy to measure, but hospital admission rates disclose the most severe episodes and consequently represent a relevant indicator of the burden of uncontrolled asthma in a population that has access to hospitals $[7,8]$.

Salvador City is the capital of the State of Bahia, located in the north eastern region of Brazil. Its population is 2.8 million inhabitants. The proportional national gross product per capita estimate for Salvador is currently U\$2,700. A major proportion of the city's population has no supplementary health insurance and is covered only by the universal public-health policies [9, 10]. It has one of the highest prevalence rates of asthma symptoms in the country [11]. In 2003, the Programme for Control of Asthma in Bahia (ProAR), prioritising care for patients with severe asthma, was implemented by the Federal

Earn CME accreditation by answering questions about this article. You will find these at the back of the printed copy of this issue or online at www.erj.ersjournals.com/misc/cmeinfo.dtl

AFFILIATIONS

*Escola de Enfermagem,

Universidade Federal da Bahia,

\#Programa para o Controle da Asma na Bahia, Faculdade de Medicina da Bahia, Universidade Federal da Bahia "Instituto de Ciências da Saúde Universidade Federal da Bahia, ${ }^{\S}$ Instituto de Saúde Coletiva, Universidade Federal da Bahia, +Hospital Especializado Octávio Mangabeira, Secretaria de Saúde do Estado da Bahia, Salvador, Brazil, ${ }^{f}$ London School of Hygiene and Tropical Medicine, University of London, London, UK, **University Hospital, and \#\#INSERM, Montpelier, France.

CORRESPONDENCE

A.A. Cruz

Programa para o Controle da Asma na Bahia

Centro de Saúde Carlos Gomes Rua Carlos Gomes 270

70. andar 40060-330 Salvador Bahia

Brazil

E-mail: acruz@ufba.br

Received:

June 272009

Accepted after revision:

July 222009

First published online:

July 302009 
University of Bahia School of Medicine in Salvador. A preliminary prospective analysis of the first 269 subjects with severe asthma followed up for 1 yr by ProAR central reference clinic reported a reduction of $85 \%$ in emergency department visits, $90 \%$ in hospitalisations and $67 \%$ in oral corticosteroids use [12].

The aim of this study was to identify trends in asthma hospitalisation rates and to evaluate the impact of ProAR in the entire city of Salvador. This was carried out by analysing and comparing trends in asthma hospitalisation rates before (19982002) and after implementation of ProAR (2003-2006). The trends of asthma admissions in Salvador were compared further to those in Recife, the metropolis in Brazil most similar to Salvador; and also to trends of hospitalisations due to pneumonia and myocardial infarction in Salvador.

\section{METHODS}

\section{Study design}

Analysis of routine data from the public health system on asthma hospitalisations for the entire city of Salvador, before and after an intervention focused on the most severe cases of asthma. This study evaluated the impact of an intervention targeted at individuals at high risk, over the hospitalisation rates of their whole community. We choose this indicator as a marked early reduction was noticed while monitoring the public health database. We decided not to include the impact on mortality in this analysis as: 1) the number of deaths was small and variable; 2) validation of death certificates takes time; and 3) trends are not consistent and will require much longer observation for accurate interpretation. In a previous study of the cohort of subjects with severe asthma followed up in ProAR central reference clinic, a steep reduction in heath resource utilisation was detected, comprising hospitalisations and emergency visits. We did not include an evaluation of emergency visits in this study because there is no specific information on this indicator of morbidity for the entire population of Salvador in the public health database. Correspondent analysis of another city with similar characteristics was undertaken for comparison. Additional information on hospitalisations due to pneumonia and myocardial infarction in Salvador was obtained as a local control for possible variations in accessibility of health services. The number of patients enrolled in ProAR and the number of those receiving inhaled corticosteroids were also taken for analysis.

\section{Setting}

ProAR is a public health intervention project supported by rules of the Brazilian Ministry of Health issued in 2002, which offered reimbursement for the costs of optimal medication to treat severe asthma. It aims to assist patients with a confirmed diagnosis of severe asthma from the large underprivileged urban population who are treated in the public health system of Brazil but cannot afford the medication necessary to prevent exacerbations. Immediate priority was given to the most severe cases from Salvador, referred from emergency departments of public hospitals throughout the city. The major role of ProAR has been to catalyse an initiative that combines contributions of all levels of public health administration (city, state and Ministry of Health) into a programme that involves healthcare, capacity building and research.
ProAR is comprised of four reference centres for specialised free medical care, pharmaceutical assistance (inhaled medication) and patient education. The education intervention was undertaken individually at the medical consultation and subsequently reinforced by the nurse and the pharmacist, as described elsewhere [13]. Moreover, all patients were encouraged to attend a monthly group session with members of the ProAR professional team, including a psychologist, where they were offered short classes on varied topics related to asthma prevention and treatment and also given plenty of time to discuss questions and concerns. We feel this is important to overcome phobias and beliefs that threaten compliance to treatment.

The reference clinics are accessible to all individuals and free of charge. A specialist checked that the referred patients performed a spirometry test and any additional tests as required. Those with severe asthma according to the Global Initiative for asthma [13] were treated with regular use of combined inhaled corticosteroid (beclomethasone or budesonide) and a long-acting $\beta_{2}$-agonist (formoterol) for maintenance, plus a short-acting inhaled $\beta_{2}$-agonist (salbutamol or fenoterol), as needed, for rescue in accordance with current international guidelines [13]. Patients with persistent rhinitis received topical nasal beclomethasone concomitantly, as recommended by the Allergic Rhinitis and its Impact on Asthma initiative [14]. Educational sessions for patients and family members emphasised secondary prevention and early control of exacerbations. A particular effort was placed on improving compliance to treatment, and has resulted in a rate of objectively measured adherence of $83 \%$ [13]. From December 2002 to December 2006, 1,895 patients with severe asthma entered the programme. The research projects associated with ProAR were approved by the ethics committee of Faculdade de Medicina da Bahia (Salvador), and all subjects enrolled were asked to sign an informed consent form.

While the reference centres offered specialised care and free medication to patients with severe asthma, in order to increase the capacity for the management of mild-to-moderate asthma, the most experienced staff of ProAR trained 512 primary healthcare physicians, nurses, pharmacists, social workers and managers between 2003 and 2006 on the prevention and management of asthma and rhinitis. To disseminate the information of the availability of ProAR to patients with severe uncontrolled asthma, flyers containing general information, and the address and telephone number of the central reference clinic were made available to all major public hospitals in the city, with special attention being paid to emergency department staff.

\section{Study population}

Data on hospitalisations were collected from all events registered in the city of Salvador. Events do not represent the number of hospitalised patients, but the number of admissions that occurred in hospitals of Salvador among residents from the city. For comparison, we collected the same information from the comparable city of Recife, which is situated in the north east of Brazil. Salvador and Recife share similarities such as asthma prevalence, population ethnicity, climate, types and distribution of common allergens and socioeconomic status. Frequency of wheezing in the last year among adolescents was 
TABLE 1 Characteristics of the population in the Brazilian cities of Salvador and Recife

\begin{tabular}{lll} 
Characteristics & Salvador & Recife \\
\hline Proportion of females & 52.9 & 53.5 \\
Proportion $>10$ yrs & 83.0 & 83.2 \\
Prevalence of wheezing in the last 12 months among adolescents & 24.6 & 19.1 \\
\hline Data are presented as \%. Data taken from [11]. &
\end{tabular}

recently reported as $24 \%$ in Salvador and $19 \%$ in Recife [11] (table 1). Recife, like most other cities in Brazil, does not have a comparable established asthma focused control programme, but several institutional and individual clinics do provide care for patients with asthma of varied age groups who have no regular provision of free medication.

\section{Data sources, variables and measurements}

Data on hospital admission events from each month from January 1998 to December 2006 were obtained from the national statistical database (DATASUS) [4]. DATASUS is a national database that is compulsorily completed from standardised hospital admission authorisation forms throughout the whole of Brazil. These forms are completed by attending physicians at each hospital in Brazil in order to request payment and are then confirmed by audit. Subsequently, only one centre, located in Brasilia, manages the database and offers free access to the information. Other studies using this database have been published [15]. We decided not to include mortality data from death certificates in this analysis as population data on cause of death is available only for earlier years. Death certificates are validated prior to their availability in the public database and it delays the process.

The number of hospitalisation events due to asthma was collected according to the place of residence of each individual (Salvador City), International Classification of Diseases-10, age group and sex. The number of hospitalisation events was converted into hospitalisation rate and analysed separately according to sex and two age groups: $<10$ yrs and $>10$ yrs. The age cut-off matches the age-specific criteria adopted by ProAR for case management and registries in the reference centres.

Trends in hospital admissions related to pneumonia and acute myocardium infarction in Salvador were analysed and compared to those for asthma to evaluate the possibility of bias from the public database system and to control for any artefact caused by variation in access to hospital care. The number of units of inhaled corticosteroids and fixed combination of corticosteroids and long-acting $\beta_{2}$-agonist bronchodilator was obtained from the pharmacies supplying medication to patients from ProAR.

\section{Analysis of the data}

The number of hospitalisation events was converted into asthma hospitalisation rates by dividing the absolute number of events per local and year-by-year population of each city, and multiplied them by 10,000 inhabitants. The procedure was carried out to avoid bias due to migration seasonality and variations in population numbers caused by birth and deaths in general.

Descriptive data are expressed as mean \pm SD. Linear regression modelling was performed to analyse trends and calculate differences between mean rates. The linearity equation used was:

$y=\beta 0+\beta 1 x$

where $y$ is the hospitalisation rate, $x$ is the calendar year; $\beta 0$ the median rate and $\beta 1$ the median increment. Linear regression results are represented by a $R^{2}$ following results. Statistical significance of differences between proportions was calculated using the Chi-squared test. Correlations between hospitalisation rates and dispensation of inhaled corticosteroids by ProAR were analysed by using Spearman's correlation test. Differences were considered statistically significant when $p<0 \cdot 05$.

\section{RESULTS}

\section{Asthma hospitalisations in Salvador}

18,830 events of hospitalisation for asthma were registered in Salvador from 1998 to 2006 . Hospitalisation rates due to asthma are shown in table 2 . The hospitalisation rates declined from 12.72 to 2.25 per 10,000 inhabitants $\left(R^{2}=0.873 ; p<0.001\right)$, a reduction of $82.3 \%$. The decline in hospitalisations due to asthma for the age group $<10$ yrs was $78.6 \%\left(R^{2}=0.896 ; p<0.001\right)$ and $93.7 \%\left(R^{2}=0.861 ; \mathrm{p}<0.001\right)$ for the age group $\geqslant 10$ yrs.

A greater reduction was observed from 2003 to 2006 following ProAR $(68.15 \%$ for $<10$ yrs of age and $87.5 \%$ for $\geqslant 10$ yrs of age) compared to that for 1998 to 2002 (31.8\% and $38.6 \%$, respectively) $(p<0.001)$. Hospitalisation rates for acute myocardium infarction and pneumonia did not decline over the same time period (fig. 1).

\section{Asthma hospitalisations in Recife}

Recife had a reduction of $44.82 \%$ in asthma hospitalisations from 1998 to $2006\left(R^{2}=0.906 ; p<0.001\right)$. The rate of reduction in hospitalisations was greater in Salvador than in Recife in 1998$2002(-31.76 \%$ versus $-14.45 \%$; $<<0.001)$, especially after ProAR from $2003-2006(-74.2 \%$ versus $-22.2 \%$; $<<0.001)$. The rates of hospitalisation due to asthma in 2006 were 2.25 per 10,000 inhabitants in Salvador and 17.06 in Recife.

\section{Correlation between drug dispensation and hospitalisations in Salvador}

From 2003 to 2006, ProAR dispensed 220,889 units of inhaled medication for asthma control (inhaled corticosteroids and/or bronchodilators). We found a strong inverse correlation between hospitalisation rates and drug dispensation $(-0.801$; $\mathrm{p}<0.001$ ) (fig. 2). 
TABLE 2 Asthma hospitalisation rates per 10,000 inhabitants in the Brazilian cities of Salvador and Recife from 1998 to 2006

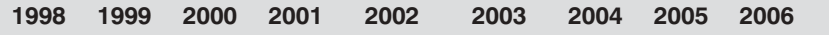

Variation
$1998-2002$

Variation 2003-2006

\begin{tabular}{|c|c|c|c|c|c|c|c|c|c|c|c|c|}
\hline \multicolumn{13}{|l|}{ Salvador } \\
\hline Frequency of hospitalisations & 2894 & 3233 & 2659 & 1972 & 2188 & 2230 & 2016 & 1027 & 611 & -706 & -1619 & -2283 \\
\hline $\begin{array}{l}\text { Hospitalisation rate per } 10000 \\
\text { inhabitants }\end{array}$ & 12.72 & 14.04 & 10.88 & 7.93 & 8.68 & 8.72 & 7.77 & 3.84 & 2.25 & $\begin{array}{c}-4.04 \\
(-31.76 \%)\end{array}$ & $\begin{array}{l}-6.47^{\# \#} \\
(-74.2 \%)\end{array}$ & $\begin{array}{c}-10.47 \\
(-82.31 \%)^{*}\end{array}$ \\
\hline \multicolumn{13}{|l|}{ Recife } \\
\hline Frequency of hospitalisations & 4230 & 4153 & 4522 & 3747 & 3834 & 3205 & 2576 & 2573 & 2585 & -396 & -620 & -1016 \\
\hline $\begin{array}{l}\text { Hospitalisation rate per } 10000 \\
\text { inhabitants }\end{array}$ & 30.92 & 30.13 & 31.78 & 26.07 & 26.45 & 21.93 & 17.48 & 17.14 & 17.06 & $\begin{array}{c}-4.47 \\
(-14.45 \%)\end{array}$ & $\begin{array}{l}-4.87^{\# \#} \\
(-22.20 \%)\end{array}$ & $\begin{array}{c}-13.86 \\
(-44.82 \%)^{\star}\end{array}$ \\
\hline
\end{tabular}

\#: variation of hospitalisation 1998-2002 (absolute and percentual); ": variation of hospitalization 2003-2006 (absolute and percentual); ${ }^{+}$: general variation of hospitalisation 1998-2006 (absolute and percentual).*: $p<0.001$ for general comparison of variation between Salvador and Recife; \#\# : $p<0.001$ for comparison between $\Delta 1$ and $\Delta 2$ in Salvador and Recife.

\section{In-hospital asthma mortality}

From 1998 to 2006, 146 in-hospital deaths were related to asthma among residents of Salvador. Asthma mortality
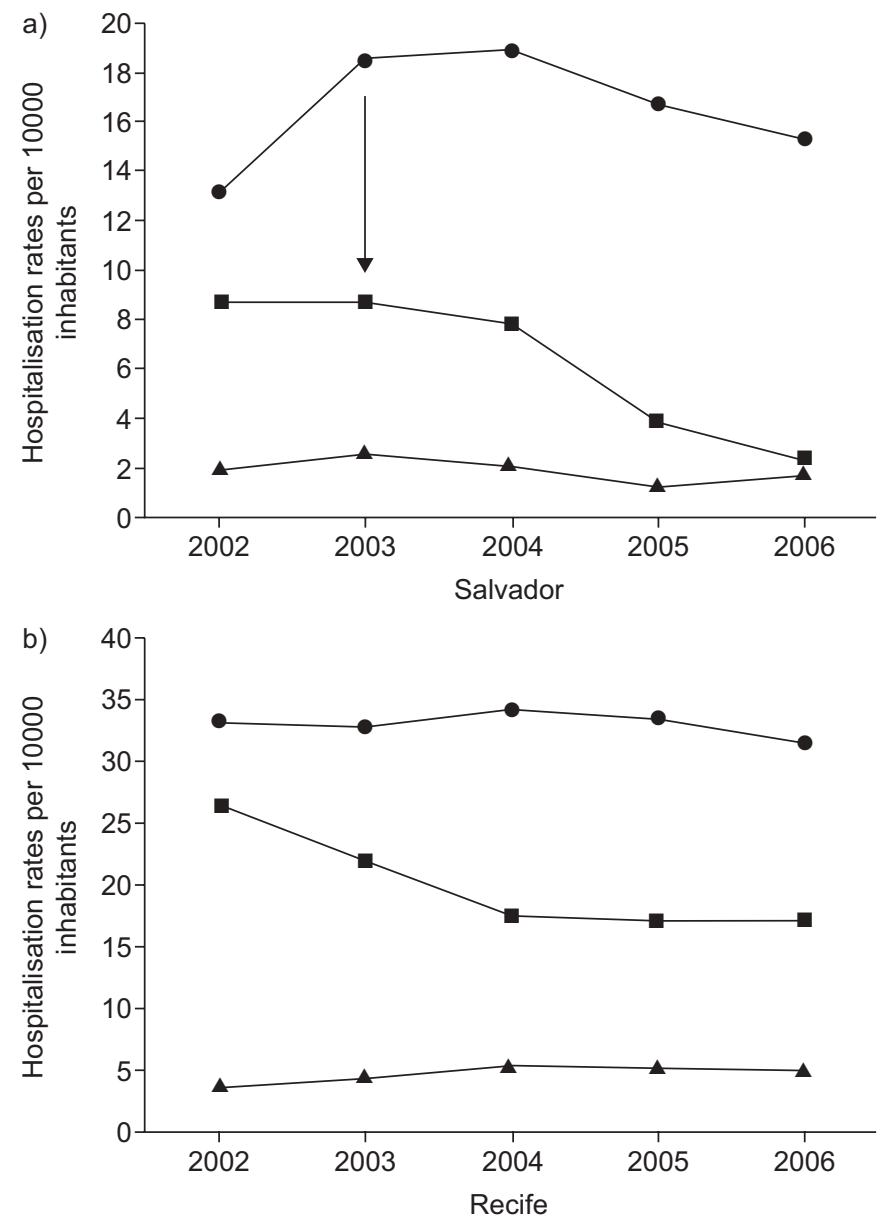

FIGURE 1. Hospitalisation rates due to asthma (অ), pneumonia $(\bullet)$ and acute myocardial infarction $(\mathbf{\Lambda})$ in the Brazilian cities of a) Salvador and b) Recife from 2002 to 2006. The arrow indicates the year the Programme for Control of Asthma in Bahia implementation started. slightly increased from 19 deaths $\cdot \mathrm{yr}^{-1}$ in 1998 to 21 deaths $\cdot \mathrm{yr}^{-1}$ in 2002. There were 23 deaths in 2003 (0.09 per 10,000 inhabitants) decreasing to only one in 2006. In Recife, the asthma in-hospital mortality rate increased from 5 deaths $\cdot \mathrm{yr}^{-1}$ in 2003 to 6 deaths $\cdot \mathrm{yr}^{-1} 2006$.

\section{DISCUSSION}

In the present study we showed a trend towards reduction in asthma hospitalisations in Salvador City from 1998 to 2006. The rate of decline seems to be enhanced after the implementation of ProAR, a government funded programme to assist patients with severe asthma of all ages. ProAR started in December 2002 and is based on the existing best evidence for case management using a multidisciplinary care approach. The decline of the asthma hospitalisation rate in Salvador was greater than that observed in Recife, a similar metropolis used as a comparison. A difference of greater magnitude was encountered between Salvador and Recife during ProAR intervention (2003-2006) than before ProAR (1998-2002).

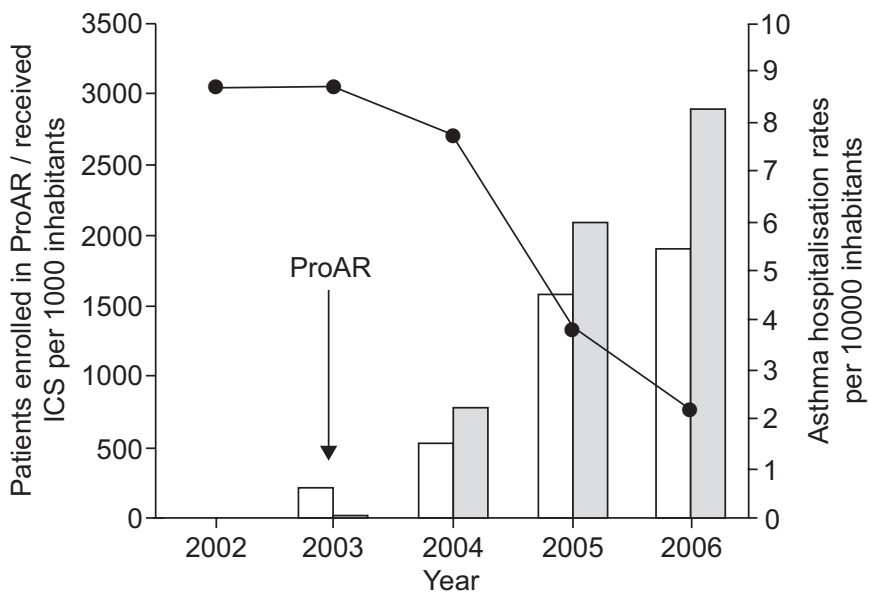

FIGURE 2. Asthma hospitalisation rates $(\bullet)$, the number of patients enrolled in the Programme for Control of Asthma in Bahia ( $\square$ ) and the number of dispensed units of medication containing inhaled corticosteroids $(\square)$ as a single medicine or in combination in Salvador, Brazil from 2002 to 2006. ICS: inhaled corticosteroids. 


\section{Limitations of the study}

The main possible limitation of the study would the greater availability of hospital beds in the public health system in Recife than in Salvador, making it easier to be hospitalised in Recife. Indeed, in 2006, the availability of beds in public hospitals in Recife was 442 per 100,000 inhabitants compared to 235 per 100,000 inhabitants in Salvador [4]. However, we noted that the proportional number of beds in Salvador has grown more than that of Recife from 1998 to 2006. This gives some assurance that the trends reported were not a consequence of differences in access to hospitalisation. On the contrary, the greater increase of availability of beds in Salvador would favour the lack of a statistical significant difference and, therefore, the null hypothesis.

Seasonal influences and possible bias in the Brazilian database register were analysed by comparison of hospitalisation rates from two distinct conditions, such as acute myocardial infarct and pneumonia. No consistent significant trends towards reduction in admissions due to these illnesses was found, which provides support to the hypothesis that the steeper decline observed for asthma admissions in Salvador was not related to accessibility to hospitalisations in the public health system or to data report, and is probably a result of the intervention by ProAR. Although we did not find any clear evidence, we cannot fully exclude the possibility that certain factors exerted influence on our observations, such as general healthcare policies, access to healthcare services and asthma diagnosis and management being different between the two cities.

Reductions in hospitalisation observed in Salvador may not be exclusively attributed to the ProAR intervention. Other factors could be a source of variation, such as changes in the quality and accessibility to the health services in the country in general. In fact, the observed general trends toward reduction in admissions due to asthma in some of the Brazilian metropolis may reflect better management of asthma, in general. Nevertheless, these factors cannot explain the steeper decline in hospitalisations rates observed in Salvador in comparison with Recife, nor the markedly lower rate of admissions due to asthma.

The number of in-hospital deaths in Salvador was small and the marked trend towards reduction observed after the implementation of ProAR will not be taken as conclusive. A much longer follow-up is necessary to allow for definitive interpretations and will be conducted.

It would be desirable to strengthen the observations of this report with other outcomes. We are relying on hospitalisations only. However, in dealing with population outcomes in a lowresource setting one cannot avoid taking into consideration hospital admissions as a good proxy of morbidity in diseases of low letality. It is relevant as it indicates risk of death and cost. We have shown a steep reduction in the number of emergency visits and oral corticosteroids utilisation, as well as better asthma control and improved quality of live in observational studies of the ambulatory cohort of subjects with severe asthma followed up by a ProAR central reference clinic [12].

\section{Interpretation}

Asthma hospitalisations were taken as the indicator of morbidity in this evaluation of the impact of ProAR as it reflects the prevalence and the severity of asthma, and may predict risk of death $[7,16]$. In the present study, asthma hospitalisation rates in Salvador were compared to those observed in Recife. Both Salvador and Recife are implementing primary healthcare programmes for the city's populations. Recife has active public health clinics providing asthma care, but has not developed yet a comprehensive programme focusing on severe asthma comparable to ProAR. Inhaled corticosteroids are the recommended therapy for control of persistent asthma. These medications were shown to reduce morbidity and mortality related to asthma $[17,18]$. Ecological studies in different countries in Latin America correlate consumption of inhaled corticosteroids inversely with asthma deaths [2]. Various studies have shown that early and intensive patient education, on top of adequate treatment, is effective in reducing emergency visits and hospitalisations among enrolled subjects from low-resource settings [6]. The novelty of the observation reported herein is the demonstration of a marked impact of a community based intervention over hospitalisations (74\% reduction) of the entire population of a city of 2.8 million inhabitants within 3 yrs. An intervention in Londrina (State of Paraná, Brazil; 500 thousand inhabitants) aimed at increasing the capacity of the primary healthcare work force and strengthening the health system for asthma control, as opposed to our prioritisation of the control of the most severe cases, has recently demonstrated a $32 \%$ reduction in asthma hospitalisations in a similar time frame [19]. In Finland, a high-income country of 5.3 million inhabitants, a $54 \%$ reduction in hospitalisations over 10 yrs was shown after their asthma programme was implemented [5]. To our knowledge, we report on the first demonstration of a rapid and dramatic impact of a targeted public health intervention for the control of asthma in a large city within a developing country.

A study comparing patients with severe asthma 1 yr before and $1 \mathrm{yr}$ after admission to ProAR reported a reduction in emergency department visits and hospitalisations of $>80 \%$ [12]. The present study is based on a public health database from which the number of hospital admissions by cause and city of residence was obtained. Due to confidentiality precautions it is not possible to know which of the patients who were hospitalised attended our intervention programme. In the future, while looking at asthma mortality and hospitalisation trends, we intend to ask for a special authorisation to perform linkage analysis combining the database of ProAR patients and DATASUS. The precise number of severe asthmatics in Salvador is unknown. However, projecting the preliminary results to the whole of the population assisted by ProAR, and considering it might avoid one hospital admission for each patient per year, $>1,000$ hospitalisations could be prevented every year. Indeed, moving from preliminary estimates to data analysis we noted that 1,619 hospitalisations due to asthma have been averted in the city of Salvador in the final year of analysis (2006). ProAR may have matched the hypothetical expectations well over the already declining trends.

The reduction of hospitalisations in Salvador was not clear from 2003 to 2004 and was only clear in 2005 and 2006. The explanation to this progressive effect, resembling a doseresponse curve, is the cumulative enrolment of patients with severe asthma, as presented in fig. 2 , which took place over the study period. 
The data presented herein reiterate the current knowledge that the more patients with asthma who have access to inhaled corticosteroids the less likely they are to be hospitalised for asthma, and adds evidence on an efficient strategic prioritisation for community interventions for control of asthma that may be extremely useful in communities of limited resources.

The intervention for control of asthma implemented by ProAR comprises a multifaceted approach including several interrelated crucial steps: 1) screening of referrals for asthma severity; 2) differential diagnosis and investigation of comorbidities; and 3) treatment planning, pharmaceutical assistance and education. All of these three items have previously been proven to be important for case management. In this study we assessed the whole of the approach and we cannot draw any inference from the role of individual components.

The high proportion of adherence to the treatment we have reported in ProAR [13] certainly contributes to the favourable results. It was made possible by the provision of free medications. It would be very difficult to obtain a comparable rate of compliance within this low-resource setting had the patients needed to pay for their care or their medication.

Some studies have raised concerns regarding the long-term safety of long-acting $\beta_{2}$-agonist bronchodilators, which might be associated with risk of hospital admissions and deaths [2022]. Our results indicate that any potential risk of hospitalisations has been largely surpassed by the benefit of our approach to the management of severe asthma, including the use of combined long-acting $\beta_{2}$-agonists and inhaled corticosteroids as recommended by current guidelines.

\section{Generalisability}

Asthma is a global health problem, which causes relevant morbidity, numerous deaths and high costs to the families and to the health systems $[1,2]$. The costs of asthma are related to the severity of disease [1] and hospitalisations represent $50 \%$ of all the expenditures with asthma [23, 24]. A study of costeffectiveness performed to evaluate ProAR showed that the intervention resulted in incremental economy to patients, their families, and the health system [25].

Although asthma hospitalisations have decreased in recent years in Brazil, in large urban centres such as Recife and Salvador hospitalisations have decreased slowly since 1998 (table 2). In Salvador, the implementation of ProAR in 2003 has probably accelerated these declining trends. In the present study the number of inhaled medications dispensed for asthma control was inversely correlated with hospitalisation rates.

The most important novel observation of this study is the rapid reduction in asthma admissions in a city of 2.8 million inhabitants after a focused intervention targeting patients at greater risk. This observation needs to be reproduced in other locations as it would be of remarkable importance to public health in countries with high morbidity due to asthma and limited resources. We speculate that the most important factors that determined our favourable results were: 1) a considerable proportion of patients with severe asthma with no access to good quality care, including affordable medication at baseline; 2) establishment of treatment with the most effective and safe medications; 3) an education programme to increase compliance to proper medication use and 4) a referral system made easy for patients and the health services. Given these four conditions it seems unlikely that a similar intervention may fail.

\section{Conclusion}

A public health intervention for asthma control targeted at the most severe cases, providing free health care and medication was associated with a rapid reduction in asthma hospital admissions in Salvador, Brazil.

\section{SUPPORT STATEMENT}

Funding for this study was provide by: Fundação de Amparo a Pesquisa da Bahia (Salvador, Brazil), Coordenação de Aperfeiçoamento de Pessoal de Nível Superior (Brasília, Brazil), Conselho Nacional de Desenvolvimento Científico e Tecnológico (Brasília) and the Social Change, Asthma and Allergy in Latin America project (Welcome Trust, London, UK). The sponsors provided scholarships and grants for postgraduate students and faculty members, to cover expenditures incurred with administration and training in ProAR. They had no role in data management or analysis, or in the preparation of this report.

\section{STATEMENT OF INTEREST}

None declared.

\section{ACKNOWLEDGEMENTS}

We would like to thank all the staff of ProAR for their technical assistance, especially A. Tereza Campos (administrator), and D. Ramos, D. Naiane and F. Silva (undergraduate students) for their important support.

\section{REFERENCES}

1 Bousquet J, Bousquet PJ, Godard P, et al. The public health implications of asthma. Bull World Heath Organ 2005; 83: 548-554.

2 Neffen H, Fritscher C, Schacht FC, et al. Asthma control in Latin America: the asthma insights and reality in Latin America (AIRLA) survey. Rev Panam Salud Publica 2005; 17: 191-197.

3 Asher MI, Montefort S, Björkstén B, et al. Worldwide time trends in the prevalence of symptoms of asthma, allergic rhinoconjunctivitis, and eczema in childhood: ISAAC Phases One and Three repeat multicountry cross-sectional surveys. Lancet 2006; 368: 733-743.

4 Ministério da Saúde do Brasil. Informações de Saúde. Departamento de Informática do SUS. www.datasus.gov.br/ tabnet/tabnet.htm Date last accessed: July 25, 2006.

5 Haahtela T, Tuomisto LE, Pietinalho A, et al. A 10 year asthma programme in Finland: major change for the better. Thorax 2006; 51: 663-670.

6 Fischer GB, Camargos PA, Mocelin HT. The burden of asthma in children: a Latin American perspective. Paediatr Respir Rev 2005; 6: 8-13.

7 Suissa S, Ernst P. Inhaled corticosteroids: impact on asthma morbidity and mortality. J Allergy Clin Immunol 2001; 107: 1-11.

8 Anderson HR, Ayres JG, Sturdy PM, et al. Bronchodilator treatment and deaths from asthma: case-control study. BMJ 2005; 330: 117-120.

9 Ministério da Saúde do Brasil. Secretaria de Atenção à Saúde. http://w3.datasus.gov.br/datasus/index.php?area=0204 Date last accessed: June 26, 2007.

10 IBGE. Instituto Brasileiro de Geografia e Estatística. Produto interno bruto a preços correntes e produto interno bruto per capita segundo as grandes regiões, unidades da federação e municípios. www.ibge.org.br Date last accessed: June 30, 2006.

11 Solé D, Camelo-Nunes IC, Wandalsen GF, et al. Is the prevalence of asthma and related symptoms among Brazilian children related to socioeconomic status? J Asthma 2008; 45: 19-25. 
12 Ponte E, Franco RA, Souza-Machado A, et al. Impact that a program to control severe asthma has on the use of Unified Health System resources in Brazil. J Bras Pneumol 2007; 33: 15-19.

13 Santos P de M, D'Oliveira A Jr, Noblat L de A, et al. Predictors of adherence to treatment in patients with severe asthma treated at a referral center in Bahia, Brazil. J Bras Pneumol 2008; 34: 995-1002.

14 Bousquet J, Van Cauwenberge P, Khaltaev N, et al. Allergic rhinitis and its impact on asthma. J Allergy Clin Immunol 2001; 108: S147S334.

15 Okie S. Fighting HIV: lessons from Brazil. N Engl J Med 2006; 54: 191-197.

16 Souza-Machado A, Souza-Machado C, Silva DF, et al. Causes of death in asthma patients enrolled in the Bahia State Program for the Control of Asthma and Allergic Rhinitis. J Bras Pneumol 2007; 33: $372-379$.

17 Lasmar L, Goulart E, Sakuri E, et al. Fatores de risco para hospitalizações de crianças e adolescentes asmáticos. Rev Saúde Pública 2002; 36: 409-419.

18 Suissa S, Ernst P, Benayoun S, et al. Low-dose inhaled corticosteroids and the prevention of death from asthma. N Engl J Med 2000; 343: 332-336.
19 Cerci Neto A, Ferreira Filho OF, Bueno T, et al. Reduction in the number of asthma-related hospital admissions after the implementation of a multidisciplinary asthma control program in the city of Londrina, Brazil. J Bras Pneumol 2008; 34: 639-645.

20 Pearce N, Beasley R, Crane J, et al. End of the New Zealand asthma mortality epidemic. Lancet 1995; 345: 41-44.

21 Salpeter SR, Buckley NS, Ormiston TM, et al. Meta-analysis: effect of long acting beta-agonists on severe asthma exacerbations and asthma-related deaths. Ann Intern Med 2006; 144: 904-912.

22 Nelson HS, Weiss ST, Bleecker ER, et al. The Salmeterol Multicenter Asthma Research Trial: a comparison of usual pharmacotherapy for asthma or usual pharmacotherapy plus salmeterol. Chest 2006; 129: 15-26.

23 Cisternas MG, Blanc PD, Yen IH, et al. A comprehensive study of the direct and indirect costs of adult asthma. J Allergy Clin Immunol 2003; 111: 1-11.

24 Smith DH, Mlone DC, Lawson KA, et al. A national estimate of economic cost of asthma. Am J Respir Crit Care Med 1997; 156: 787-793.

25 Franco R, Santos AC, Nascimento HF, et al. Cost-effectiveness analysis of a state funded programme for control of severe asthma. BMC Public Health 2007; 82: 1-8. 